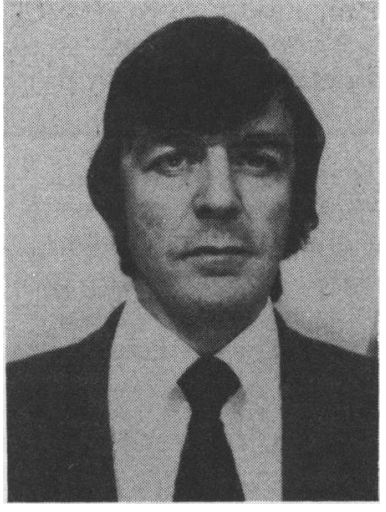

B. Davies

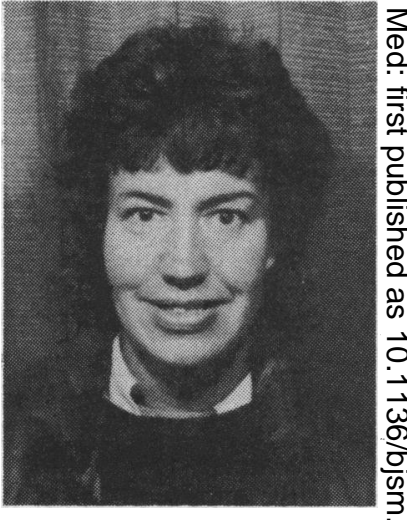

Anne Daggett

\title{
PHYSIOLOGICAL CHANGES AND SLEEP RESPONSES DURING AND FOLLOWING A WORLD RECORD CONTINUOUS WALKING RECORD
}

\author{
B. DAVIES, MSc, PhD, FACSM*, C. M. SHAPIRO, MSc * , A. DAGGETT, MSc*, \\ J. A. GATT, BSct and P. JAKEMAN, MSc* \\ *Human Performance Laboratory, University of Salford, England \\ * "University Department of Psychiatry, Royal Edinburgh Hospital \\ tDepartment of Biochemistry, Preston Royal Infirmary
}

\begin{abstract}
Physiological changes, and subsequent sleep responses, were recorded in a male subject during and following 338 miles of continuous walking and consequent sleep deprivation. One hundred and thirty hours of walking and a seventy-two hours post-walk recovery period were monitored. The subject walked at approximately $55 \%$ of maximum oxygen $\propto$ uptake $\left(\mathrm{VO}_{2} \max \right)$, heart rate ranged between $102-106 \mathrm{~b} / \mathrm{min}$, and blood lactate (LA) remained below the $2 \mathrm{mmol} / \overrightarrow{\mathrm{O}}$ level. No electrocardiograph abnormalities were observed either during the walk or pre-and post-functional diagnostic 3 graded exercise test (FDGXT).
\end{abstract}

Creatine kinase (CK) and creatine kinase isoenzyme (CK-MB) levels rose throughout the walk but exhibited differing . depletion patterns. The ratio of CK-MB to CK (MB/CK\%) did not exceed levels which are suggestive of myocardial? ischaemia. Haematological variables demonstrated signs of anaemia towards the end of the walk. Catecholamine levelso rose throughout the walk, with greater rises being observed in nor-adrenaline and dopamine. During the post-walk recovery phase, adrenaline concentration remained elevated.

Following this extreme period of exertion, the subject demonstrated very short sleep latency and rapid entry intoo slow wave sleep (SWS). These sleep patterns were compared to sleep recordings made over a similar period $(72 \mathrm{~h}$ ) six months post-walk, when the subject was not exercising. Nocturnal growth hormone (GH) levels were significantlyo raised on the post-walk nights.

Key words: Continuous exercise, Sleep deprivation, Hormones, Enzymes, ECG.

Address for correspondence:

Dr. Bruce Davies

Chairman

Department of Human Kinetics

University of Salford

Salford M5 4WT

Lancashire

England

\section{INTRODUCTION}

An attempt on the world continuous walking record $\stackrel{\mathbb{S}}{+}$ provided a unique opportunity to study, in detail, the 0 physiological, haematological and hormonal responses to $130 \mathrm{~h}$ of continuous walking and consequent sleep deprivation on a male subject. 
A deterioration in both physiological and psychological function during moderate intensity work, over a period of $100 \mathrm{~h}$, has previously been recorded (Thomas and Reilly, 1975). Following a $\mathbf{3 1 2}$ mile, 20 day road race, Dressendorfer and Wade (1980) reported changes indicative of traumatic haemolytic anaemia. Significant increases in serum enzymes have been observed, following $\mathbf{1 0 0}$ miles of mountainous running (Lang et al, 1981; Superko et al, 1979) and during five consecutive days of middle distance running (Sanders and Bloor, 1975), suggesting that creatine kinase (CK), in particular, might be a sensitive index of physiological stress in well-conditioned athletes. Urine catecholamine excretion has been seen to approximately double during continuous long distance walking over $24 \mathrm{~h}$ (Townshend and Smith, 1972), and to increase ten-fold following several hours of heavy physical activity (Karki, 1958).

The effects of sleep deprivation, in general, have been reviewed (Horne, 1979), as have the effects of exercise on sleep (Shapiro, 1981). It has been shown that there is an increase in slow wave sleep (SWS), often considered to be the restorative component of sleep (Oswald, 1980), following both long and arduous forms of exercise and sleep deprivation (Shapiro et al, 1981). The interplay of these two factors has rarely been considered, and certainly never in the extreme situation, such as a continuous long distance walk. The possible changes that may occur in SWS, after both exercise and sleep deprivation, are similar, i.e.,

1. Absolute increase in the amount of SWS on the recovery night,

2. A relative increase in SWS and

3. Possibly a greater intensity of SWS.

One aspect of this intensity component could be the influence of growth hormone $(\mathrm{GH})$ release, which is temporarily closely linked to SWS (Honda et al, 1969).

This study examined the physiological, haematological and hormonal responses to 338 miles of continuous walking over $130 \mathrm{~h}$, and the post-exercise (and sleep deprivation) sleep patterns during the subsequent three days of recovery.

\section{METHODS}

The subject was a 47 year old male who had previously completed two 'non-stop' walking records of more than 300 miles, and numerous walking races of 100 miles distance. Six months prior to the record attempt, the subject trained by completing walks of $30-40$ miles duration during the evening hours.

The subject was medically examined and underwent a functional diagnostic graded exercise test (FDGXT) on a treadmill prior to and six weeks following the walk. During both exercise tests a precordial V5 lead ECG, blood pressure and oxygen consumption were continuously monitored until maximum oxygen $\left(\mathrm{VO}_{2}\right.$ max) was obtained (Table 1). Blood lactate was ascertained pre-, two and five min post-test, from pin prick samples.

\section{TABLE I}

Pre- and post-walk functional graded exercise tests.

\begin{tabular}{|c|c|c|}
\hline Measurement & $\begin{array}{c}\text { Test } 1 \\
\text { Pre-walk }\end{array}$ & $\begin{array}{c}\text { Test } 2 \\
6 \text { months' } \\
\text { post-walk }\end{array}$ \\
\hline $\mathrm{VO}_{2}(\mathrm{I} / \mathrm{min})$ & 2.98 & 2.45 \\
\hline $\mathrm{VO}_{2} \max \left(\mathrm{ml} \cdot \mathrm{kg}^{-1} \mathrm{~min}^{-1}\right)$ & 41.4 & 33.6 \\
\hline VE $(1 / \min )$ & 119.5 & 95.3 \\
\hline R (Respiratory Exchange Ratio) & 1.28 & 1.14 \\
\hline $\mathrm{Hb}(g / d l)$ & 13.0 & 13.1 \\
\hline PCV (\%) & 42 & 43 \\
\hline Bodyweight (kg) & 68.2 & 73.0 \\
\hline Heart rate $(b / \mathrm{min})$ & 180 & 176 \\
\hline HLA (mmol/I) & 9.8 & 12.2 \\
\hline
\end{tabular}

The walk area consisted of a flat circular track, 1.8 miles in perimeter. Prior to, and at the same time each day during the walk, blood samples $(10 \mathrm{ml})$ were obtained from a forearm vein. Samples were stored, and subsequently analysed for creatine kinase (CK), creatine kinase isoenzyme $M B$ (CK-MB), serum electrolytes, prolactin (PRL), growth hormone $(G H)$, haemo-? globin (Hb), pack cell volume (PCV), and glucose (G). Every urine sample was collected throughout the walk period, and 24 hour pooled samples were collected during the recovery phase for analysis of catecholamine levels (adrenaline, nor-adrenaline and dopamine).

Throughout the six days of the walk, and three days recovery phase, blood pressure and body temperature were recorded at exact intervals. Heart rates were recorded continuously from a bipolar (CM5) lead, using a lightweight pocket-size tape recorder (MEDILOG).

Within one hour post-walk, the subject was transported to hospital and electrodes attached for the monitoring of electroencephalograph (EEG), electromyograph (EMG) and electro-oculargraph (EOG). Sleep records were monitored for $72 \mathrm{~h}$ and were subsequently scored according to the standard criteria (Rechtschaffen and Kales, 1968). Blood samples were obtained, without disturbing the sleeping subject, at $20 \mathrm{~min}$. intervals, during all sleep periods, via an indwelling catheter connected to an extension lead. Growth hormone was measured every $20 \mathrm{~min}$ during the sleep period. Growth hormone levels were then plotted and a profile ascertained from the area under the obtained curve. This provides a standard method for nocturnal hormone secretion.

Six months following the walk, the subject returned 
to the laboratory where all initial tests were repeated. Seven months post-walk, the sleep patterns, GH and PRL release was again monitored for three days. These two testing sessions provided a reference point for this subject, when not exercising strenuously.

\section{BIOCHEMICAL AND HAEMATOLOGICAL ANALYSIS}

Blood samples collected during the walk were centrifuged at 3,000 rpm, within one hour of collection. Electrolytes were analysed immediately (Technicron SMA). The remaining serum was stored at $-20^{\circ} \mathrm{C}$ prior to analysis for CK (Boehringer-Mannheim CK-NAC activated) and CK-MB (Boehringer-Mannheim), utilising mini-column adapted from the method of Mercer (1974). GH was analysed by radioimmunoassay (RIA) technique (Wellcome) and prolactin by RIA (Netria). Lactate levels were analysed according to the methods of Guttman and Waklefeld (1974), and blood glucose by glucose oxidase method (Boehringer-Mannheim test combination). Measurement of urinary catecholamines was performed by preliminary extraction on to allumina (aluminium oxide), followed by separation and quantitation, using high performance liquid chromatography (Moyer et al, 1979) with amperometric detection.

Whole blood samples were analysed for $\mathrm{Hb}$ and PCV (Coulter Counter Model S). Blood samples collected during both the recovery and baseline sleep studies were immediately centrifuged and then separated and stored at $-20^{\circ} \mathrm{C}$ for subsequent analysis which were carried out on all samples at the same time.

\section{RESULTS}

The subject completed the walk in $130.8 \mathrm{~h}$, and his distance 338.2 miles was a new world record for continuous walking. Actual walking time represented $98.6 \%$ of the elapsed time, the remaining $1.4 \%$ of the time being utilised for essential toilet and medical stoppages. Mean daily walking speed ranged from $3.5 \mathrm{mph}$ on Day 1 to $1.9 \mathrm{mph}$ on Day 6 (Table II). Daily mileage declined from the 83.7 miles completed on Day 1 to the 57 miles completed on Day 5 (Table II). Lowest night time ambient temperatures ranged from $1.3^{\circ} \mathrm{C}$ to $7.2^{\circ} \mathrm{C}$, and highest day time temperature from $10.2^{\circ} \mathrm{C}$ to $12.6^{\circ} \mathrm{C}$. Barometric pressure and humidity remained stable, and precipitation was minimal throughout the walk period. Heart rate averaged $105 \mathrm{~b} / \mathrm{min}$ and no ECG abnormalities were observed during the walk. The subject walked at approximately $55 \%$ of $\mathrm{VO}_{2}$ max throughout the six days, with lactate levels remaining below the $2 \mathrm{mmol} / \mathrm{l}$ level (Table II). Total weight loss during the walk amounted to $4.6 \mathrm{~kg}$ with energy expenditure being estimated at $33.5 \mathrm{~mJ}$ Calories a day (Durnin and Passmore, 1967). CK activity rose to a peak level on Day 3 and gradually declined throughout the walk and during the recovery phase, but did not return to the levels ascertained prior to the walk (Fig. 1). CK-MB demon-
TABLE II

Profile of the non-stop walking record $(130.2 \mathrm{~h})$

$\begin{array}{lccccccc}\text { Day } & \begin{array}{c}\text { Daily } \\ \text { distance } \\ \text { (miles) }\end{array} & \begin{array}{c}\text { Total } \\ \text { distance } \\ \text { (miles) }\end{array} & \begin{array}{c}\text { Speed } \\ \text { (mph) }\end{array} & \begin{array}{c}\text { Heart } \\ \text { rate } \\ \text { (b/min) }\end{array} & \begin{array}{c}\text { Lactate } \\ \text { (mmol/I) }\end{array} \\ \text { Start } & - & - & - & 65 & 0.8 & \\ 1 & 83.7 & 83.7 & 3.5 & 106 & 1.2 & \\ 2 & 67.6 & 151.3 & 2.8 & 107 & 1.2 & \\ 3 & 55.2 & 206.5 & 2.3 & 106 & 1.3 & \\ 4 & 53.4 & 259.9 & 2.3 & 105 & 1.8 & \\ 5 & 57.0 & 316.9 & 2.4 & 105 & 1.5 & \\ 6 & 21.4 & 338.2 & 1.9 & 102 & 1.3 & \\ \text { (10 hours) } & & & & & & \end{array}$

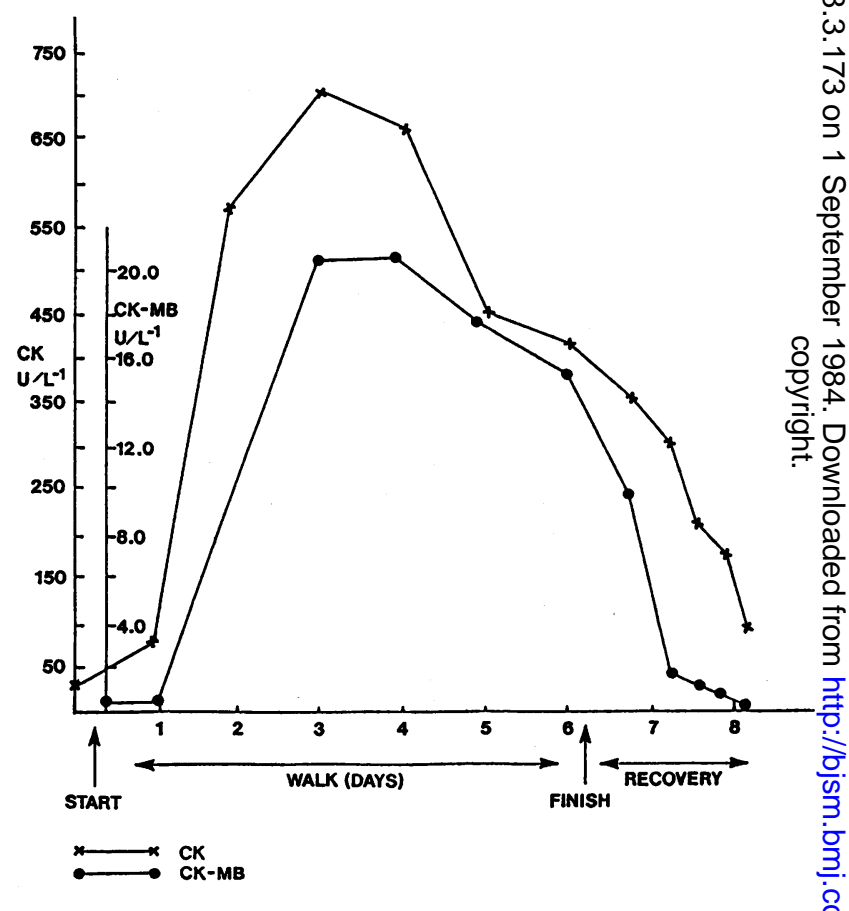

Fig. 1: $C K, C K-M B$ Excretion throughout the walk and recovery phase.

strated smaller increases, with the peak being achieved on Day 3 and then remaining stable until the recovery o phase, when levels achieved their pre-walk status (Fig.N 1). The percentage of MB to $\mathrm{CK}$ (MB/CK\%) followed a similar pattern, but never exceeded the levels which are suggestive of myocardial ischaemia (Marmour et al, 1979). Normal ranges obtained in our laboratory are:? CK-MB (0.0-1.3 $\left.\mu / L^{-1}\right), C K\left(18-60 \mu / L^{-1}\right)$ and MB/CK\% (<2.0\%).

Electrolyte changes were minimal, but some differ-市 ences were discovered between the walk and recovery $\frac{\Omega}{\Phi}$ 
phase. Urea rose throughout the walk period, to decline again during the recovery phase. Only total protein exceeded the normal levels, with rises up to $86 \mathrm{~g} / \mathrm{l}$ in the early stages of recovery. Elevated GH levels were detectable throughout the walk phase and for $16 \mathrm{~h}$ into the recovery phase and ranged from 48 to $29 \mathrm{mmol} / \mathrm{l}$ respectively. In contrast PRL levels remained with in the normal range (141-255 mmol//) during the walk. Urinary catecholamine responses during the walk demonstrated slight rises in adrenaline, with greater changes in noradrenaline and dopamine (Fig. 2). During the first $30 \mathrm{~h}$ of the recovery period, adrenaline remained stable, but nor-adrenaline and dopamine decreased markedly. During the final stages of the recovery period $(3 \mathrm{~h}$ prior to leaving hospital), all catecholamine levels became elevated once again.

Haemoglobin concentrations decreased from a prewalk level of $13.0 \mathrm{~g} / \mathrm{dl}$ to $11.6 \mathrm{~g} / \mathrm{dl}$ on Day 8, with PCV demonstrating a similar decline of $42 \%$ to $34 \%$. During the walk, urinary myoglobin did not change and serum haptoglobin increased from $204-287 \mathrm{ng} / 100 \mathrm{ml}$.

Comparison of the pre- and post-walk (6 months) metabolic tests illustrate the decline in fitness status of the subject during the six months period of inactivity, with a $19 \%$ decrease in $\mathrm{VO}_{2}$ max being observed (Table 1).

The increase in sleep time on the first post-walk night is shown in Table III, together with the comparison of sleep patterns on the three post-walk nights. The subject demonstrated very short sleep latency and rapid entry into slow wave sleep (SWS) after the walk. The relative and absolute levels of SWS remained high for the three nights, but showed a rapid decline during the third night (Table III). When compared with the 'baseline' GH profile lobtained during sleep recorded seven

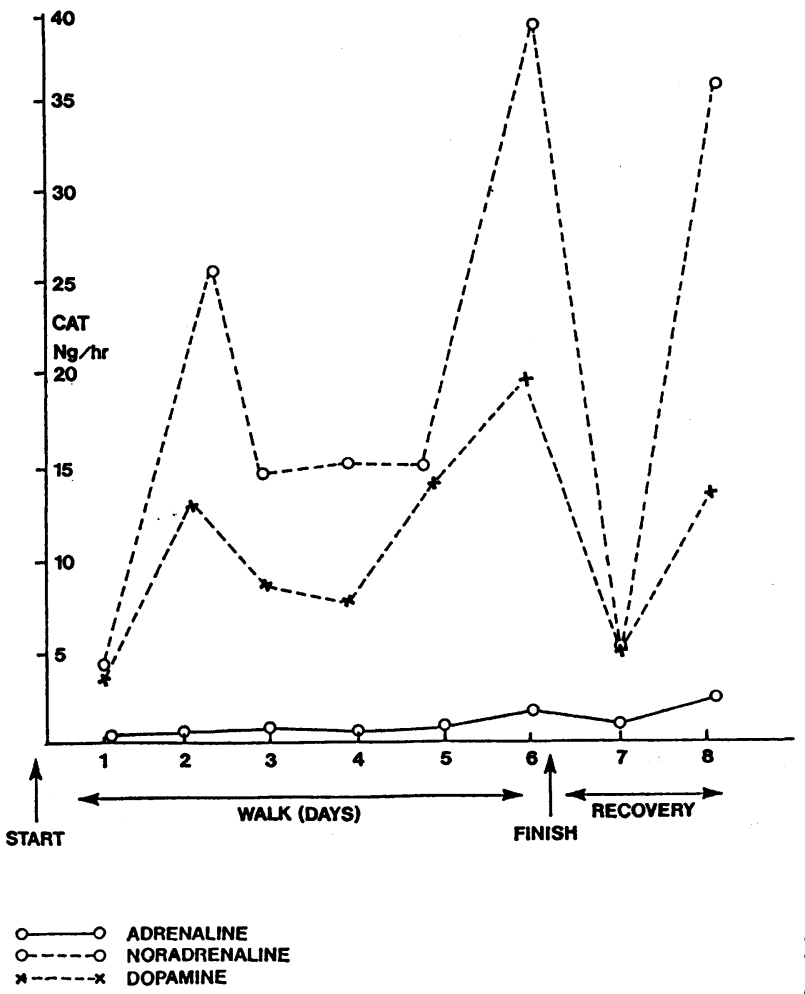

Fig. 2: Catecholamine Excretion throughout the walk and recovery phase.

months after the walk) total GH on the first of the postwalk days was increased by $93 \%$ and total secretion of GH over the three post-walk days was $37 \%$ greater than the three 'baseline' days.

TABLE III

Total sleep time and percentage of time in each sleep stage on three nights following the walk.

\begin{tabular}{|c|c|c|c|c|c|c|c|c|c|}
\hline \multirow[b]{2}{*}{ Occasion } & \multirow[b]{2}{*}{$\begin{array}{c}\text { Duration } \\
\text { of sleep } \\
\text { (mins) }\end{array}$} & \multicolumn{8}{|c|}{ Stage (\%) } \\
\hline & & $\begin{array}{c}0 \\
\text { Awake }\end{array}$ & 1 & 2 & 3 & 4 & REM & Movement & $\begin{array}{l}\text { SWS } \\
(3+4)\end{array}$ \\
\hline Afternoon 1 & 153 & - & 1.9 & 13.0 & 8.4 & 73.8 & 0 & 2.6 & 82.2 \\
\hline Night 1 & $525^{\circ}$ & 3.6 & 3.4 & 39.4 & 10.8 & 24.0 & 12.1 & 6.4 & 34.8 \\
\hline $\begin{array}{l}\text { Day } 1 \\
\text { (afternoon } \\
+ \text { night) }\end{array}$ & 678 & 2.8 & 3.0 & 33.4 & 10.3 & 35.2 & 9.4 & 5.6 & 45.5 \\
\hline Day 2 & 400 & 5.0 & 2.2 & 33.0 & 6.7 & 33.7 & 17.0 & 2.2 & 40.4 \\
\hline Day 3 & 401 & 4.9 & 3.4 & 43.6 & 6.9 & 21.6 & 17.4 & 1.7 & 29.5 \\
\hline $\begin{array}{l}\text { Normal male } \\
\text { age } 40-49\end{array}$ & 389 & 6.29 & 7.56 & 54.75 & 5.37 & 3.18 & 22.85 & - & 8.54 \\
\hline SD & 46.50 & 5.56 & 3.03 & 11.14 & 3.27 & 6.25 & 4.0 & - & 6.84 \\
\hline
\end{tabular}




\section{DISCUSSION}

The demands of physical endurance events, which result in marked sleep deprivation, may possibly require unique subject characteristics which may not necessarily manifest themselves in a superior physiological status. The pre-walk functional diagnostic treadmill test confirmed the satisfactory physiological and clinical status of the subject. The $\mathrm{VO}_{2} \max ($ Table I), was average (Åstrand and Rodahl, 1970), and not in the same range as endurance trained athletes reported in the literature (Saltin and Åstrand, 1967), demonstrating that for low intensity extreme endurance work in a high $\mathrm{VO}_{2}$ max is not a pre-requisite. In this particular walk, the metabolic requirements were not intensive. Examination of heart rate levels throughout the walk (Table II) showed that the subject was not walking at more than $55 \% \mathrm{VO}_{2}$ max at any stage. Similarly, during a 100 miles walk, average walking speeds of $4 \mathrm{mph}$ at $45 \% \mathrm{VO}_{2} \max$ and repiratory equivalent of 0.86 have been recorded (Phillips et al, 1980). No significant changes have been noted in $\mathrm{VO}_{2}, \mathrm{VCO}_{2}$ or VE at work rates of $25-75 \%$ $\mathrm{VO}_{2}$ max and $30 \mathrm{~h}$ of sleep deprivation (Martin and Gaddis, 1981). However, some authors do report a reduction in heart rate following sleep deprivation (Holland, 1968; Martin and Gaddis, 1981; Pickett and Morris, 1975). It has been suggested (Martin and Gaddis, 1981) that sleep loss might be either an activator of parasy mpathetic, or a suppressor of sympathetic activity. In this subject, heart rate remained stable for five days, with a slight decline during the final $10 \mathrm{~h}$, which corresponded to the lower work rate (Table II).

The CK and CK-MB efflux patterns are in agreement with those reported by other investigators following long-term exercise (Berg and Haralambie, 1978; Lang et al, 1981; Sanders and Bloor, 1975). It has been suggested that changes in serum enzyme activity may be affected by the type of work, its intensity and/or duration (Haralambie and Berg, 1978).

The isoenzyme CK-MB has been shown to be more exclusively related to heart muscle (Roberts et al, 1975). However, elevated skeletal muscle CK-MB has been observed in marathon runners (Davies et al, 1982). CKMB efflux, following intensive exercise has been related to ECG abnormalities in trained individuals tested in our laboratory (Davies et al, 1982). No ECG abnormalities were observed in this subject either during the walk or during the pre- and post-walk diagnostic treadmill tests. However, the CK-MB efflux and serum levels during the walk are suggestive of moderate cardiac ischaemia, because whereas total CK activity rose to a peak on Day 3, thereafter declining in relation to walking speed, CK-MB maintained a plateau from Day 3 onwards (Fig. 1). In spite of the decline in exercise intensity, heart rate remained at the same level (Table II). During the recovery phase CK-MB levels returned to the pre-walk level, with a corresponding decrease in heart rate, unlike total CK which remained elevated in relation to its prewalk level. Normal levels of MB/CK\% have been reported as $0-2 \%$ (Mercer and Varat, 1975), with levels of $4 \%$ being suggestive of myocardial ischaemia (Marmour et al, 1979). MB/CK\% levels recorded during the walk (Fig. 1) did not exceed this critical point, but it is $\frac{\partial}{0}$ interesting to note that the highest levels recorded were $\overline{\bar{m}}$ at the latter stages of the walk when the subject was $\mathbb{D}$ extremely fatigued.

Factors influencing the efflux of total CK into the bloodstream have been proposed as (1) energy deficit resulting in cell destruction and consequent release of intracellular enzymes, (2) muscle hypoxia and (3) mech- $\frac{O}{G}$. anical factors resulting from impact-type activities 3 (Berg and Haralambie, 1978; Haralambie et al, 1976). $\vec{\infty}$ Intravascular haemolysis has been observed to be quanti- $\dot{\omega}$ tively minor following a $\mathbf{1 0 0}$ mile run (Poortmans and Haralambie, 1978). Urine myoglobin was only detected $\omega$ slightly during the final stages of the walk.

Rises in CK-MB have been suggested as changes which might be indicative of transient hypoxia, secondary to ischaemia, which may precipitate alterations in membrane permeability. Under extreme stress, it has been suggested that an energy deficiency of the subo endocardial myocardium will develop with enzyme loss but without irreversible damage. In this case, the ratio of CK-MB to total CK was not high, and the demands of the walk were aerobic in nature (Table II), so it is unlikely that any ischaemia responses developed.

Considerable variation was observed in the pattern of catecholamine excretion (Fig. 2). Highest values recorded showed a nine-fold increase in adrenaline, a seven-fold increase in nor-adrenaline and a fifteen-fold increase in dopamine excretion. In all cases, these high values were recorded in conjunction with a high urinary output, suggesting a "flush out" effect with increased urine formation. This would be contradictory to the findings of Townshend and Smith (1972) who suggest that the urinary excretion of catecholamines is unaffected by either changes in renal blood flow, or by the influence of diuretics. The values obtained were within the range reported for exercise of similar intensity (von Euler, 1976) but, to the authors' knowledge, no such data is available for such prolonged periods of work. The large and somewhat inconsistent change in adrenaline, compared to the previously reported work, cannot be explained by any circadian pattem (Akerstedt and Fröberg, 1976) but rather by the variation in the stimulation of adrenomedullary activity, i.e. blood glucose, mental stress and temperature. The continued rise in nor-adrenaline is most probably due to an increased sympathoadrenal response to maintain the vasomotor system and prevent disturbance of the cardio-vascular system. What is apparent, from these results, is that there is no evidence of a reduc-

\section{.}


tion in the ability of the sympathoadrenal medullary system to cope with stress of a moderate intensity for a prolonged period of time.

The lability of $\mathrm{GH}$ release and the factors affecting this have been well documented (Shephard and Sidney, 1975). However, the changes in $\mathrm{GH}$ levels during prolonged exercise have not been examined in such detail. During seven hours of walking, fasting subjects exhibited intermittent peaks of $\mathrm{GH}$ concentration (Hunter et al, 1967) which are widely regarded as the characteristic mode of GH release (Shephard and Sidney, 1975). Following a $100 \mathrm{~km}, 8-12 \mathrm{~h}$ run, GH levels increased seven-fold, returning to pre-race levels within $24 \mathrm{~h}$ (Glutz et al, 1978). Similar increases were observed in this study during the walk phase, with $\mathrm{GH}$ levels being highest when the exercise intensity was at its greatest. A probable stimulus to $\mathrm{GH}$ release is the need for mobilisation of fat as a fuel for exercise (Metivier, 1975).

The extreme increase in SWS, following the walk, is the most significant feature of the observations on the sleep patterns following the continuous walk. This observation could be predicted from studies on the effect of exercise on sleep (Shapiro, 1981) and the known effects of sleep deprivation (Horne, 1979). Although it has been suggested that daytime exercise may result in an increase in nocturnal secretion of GH (Adamson et al, 1974), the effect of near total sleep deprivation on $\mathrm{GH}$ secretion during subsequent sleep has not previously been studied. The observations in this extreme case study of an increase in $\mathrm{GH}$ release, following the combined stress of extreme exercise and sleep deprivation, supports the restorative theory of sleep and may be one reason for the subjective impression many athletes have that their sleep, after exercise, is more "restful". A subsequent study (Shapiro et al, unpublished) on 12 subjects, has shown that the effects of sleep deprivation alone $(50 \mathrm{~h})$ produces a significant rise in $\mathrm{GH}$ release during the first two hours of recovery sleep (and a more sustained rise in prolactin secretion). The lower levels of SWS recorded during the baseline measures may, in a small way, be related to the loss of fitness that had occurred between the continuous walk and the baseline measures.

In conclusion, it would seem that a walk of this intensity is well within the physiological capabilities of an individual with average aerobic capacity. All of the physiological responses, with the exception of the developing anaemia, were within the range of normality throughout the walk. It is possible that, with iron supplementation during the training period prior to the walk (Enn et al, 1980), the fall in $\mathrm{Hb}$ and PCV could also have been prevented. However, the enormous psychological and physiological feat in overcoming the sleep deprivation (West et al, 1962; Reilly and Walsh, 1981), is illustrated in the post-exercise sleep patterns. The significant increase in SWS and the raised level of GH following the exercise and sleep deprivation, suggest that both these factors play an important role in restoration and recovery after the extreme stress of the continuous walk.

\section{ACKNOWLEDGEMENTS}

The authors wish to express their thanks to Tom Benson (World Continuous Walking Record Holder) for his cooperation throughout the study.

The assistance of Dr. I. Lang (Department of Biochemistry, Manchester Royal Infirmary) with the analysis of growth hormone, and Oxford Instruments (Medilog), is acknowledged.

This research was funded by the Preston Area Health Authority Research Committee.

\section{REFERENCES}

Adamson, L., Hunter, W. M., Ogunremi, O. O., Oswald, I. and Percy-Robb, I. W., 1974 "Growth hormone increase during sleep after daytime exercise". J.Endocr. 62: 473-478.

Akerstedt, T. and Fröberg, J. E., 1976 "Individual differences in circadian patterns of catecholamine excretion, body temperature and subjective arousal". Biol.Psych. 4: 277-292.

Åstrand, P. O. and Rodahl, K., 1970. Texbook of Work Physiology. New York: McGraw-Hill, 305-307.

Berg, A. and Haralambie, G., 1978 "Changes in serum creatine kinase and hexose phosphate isomerase activity with exercise duration". Eur.J.Appl.Physiol. 39: 191-200.

Davies, B., Daggett, A., Watt, D. A. L., 1982 "Creatine kinase and isoenzyme responses of veteran class fell runners". Eur.J.Appl.Physiol. 48: 345-354.

Dressendorfer, R. H. and Wade, C. E., 1980 "Haematological changes in runners during a 312 mile road race. American College of Sports Medicine Annual Meeting". Med.Sci. in Spts. and Exer. 12: 108. 
Durnin, J. V. G. A. and Passmore, R., 1967. Energy, Work and Leisure. London: Heinemann, 103.

Enn, L., Carlmark, B. and Hoglund, S., 1980 "Iron status in athletes involved in intense physical activity". Med.Sci. in Spts. and Exer. 12: 61-64.

Glutz, G. Von, Luthi, V. and Howard, H., 1978 "Plasma growth hormone, aldosterone, cortisol and insulin changes in a $100 \mathrm{~km}$ run". In: F. Landry and W. A. R. Orban (eds.) 3rd International Symposium on Biochemistry and Exercise. $\overline{\bar{w}}$ Miami: Symposia Specialists Inc.

Gutman, I. and Waklefeld, A. W., 1974 "L-(+)-lactate determinations with lactate dehydrogenase and NAD". Methods is of Enzymatic Analysis (2nd Ed.). New York/London: Academic Press Inc., 1464.

Haralambie, G. and Berg, A., 1978 "Creatine kinase and hexose phosphate isomerase activity in skeletal muscles of healthy male adults". Enzyme 23: 104-197.

Haralambie, G., Cerny, F. G. and Huber, G., 1976 "Serum enzyme levels after bobsled racing". J.Spots Med. and Phys. Fit. 16: 54-56.

Holland, G. J., 1968 "Effects of limited sleep deprivation on performance of selected motor tasks". Res.Quart. 39: 285-294.

Honda, Y., Takahashi, K. and Takahashi, S., 1969 "Growth hormone secretion during nocturnal sleep in normal subjects". J. of Clin.Endocr. 29: 20-29.

Horne, J. H., 1979 “Review of the biological effects of total sleep deprivation in man". Biological Psychol. 7: 55-102.

Hunter, W. M., Rignal, W. M. and Sukkar, M. Y., 1967 "Plasma growth hormone during fasting". Proc.Int.Sym危 $\vec{\varphi}$ Growth Horm. Int.Congr.Ser. 158: 408-417.

Karki, N. T., 1958 “The urinary excretions of adrenaline and nor-adrenaline in different age groups, its diurnal varia tion and the effect of muscular work on it". Acta Physiol.Scand. 39, Suppl. 132.

Lang, G., Simon, G., Lind, R. and Unterholzner, W., 1981 "Serum biochemical and enzyme changes in Western States 100 mile run. American College of Sports Medicine Annual Meeting". Med.Sci. in Spts. and Exer. 13 (2): 112.

Marmour, A., Keidar, S., Grenadir, E. and Palant, A., 1979 “MB isoenzyme of creatine phosphokinase: Indicator of ischaemia in coronary arterial disease". Chest 75 (1): 88-90.

Martin, B. J. and Gaddis, G. M., 1981 “Exercise after sleep deprivation”. Med.Sci. in Spts. and Exer. 13: 220-223.

Mercer, D. W., 1974 "Separation of tissue and serum creatine kinase isoenzymes by ion-exchange column chromatography". Clin.Chem. 20: 36-40.

Mercer, D. W. and Varat, M. A., 1975 “Detection of cardiac specific creatine kinase isoenzyme in sera with normal or slightly increased total creatine kinase activity". Clin.Chem. 21: 1088-1092.

Metivier, G., 1975 "The effects of long lasting physical exercise and training on hormonal regulation". In: H. Howard and J. R. Poortmans (eds.) Metabolic Adaptation to Prolonged Physical Exercise. Basle: Birkhauser Verlag, 276-292. N

Moyer, J. P., Joing, Nai-Siong, Tyce, M. and Sheps, G. S., 1979 “Analysis of urinary catecholamines by liquid chrom- $\mathcal{D}^{-}$ atography with amperometric detection. Methodology and clinical interpretation of results". Clin.Chem. 25 (2): 256-263.

Oswald, I., 1980 "Sleep as a restorative process: Human clues". In: M. Corner (ed.). Progress in Brain Research Vol. 50. Elsevier, 279-287.

Phillips, W. H., Suœc, A. A. and Seldere, D. J., 1980 “Oxygen consumption and energy cost during ultramarathon running and walking performance". ACSM Annual Meeting. 
Pickett, G. F. and Morris, A. F., 1975 "Effects of acute sleep and food deprivation on total body response time and cardiovascular performance". J.Spts.Med.Phys.Fit. 15: 49-56.

Poortmans, J. and Haralambie, G., 1978. Cited in Berg, A. and Haralambie, G. "Changes in serum creatine kinase and hexose phosphate isomerase activity with exercise duration". Eur.J.Appl.Physiol. 39: 191-200.

Rechtschaffen, A. and Kales, A., 1968. A Manual of Standardised Terminology, Techniques and Scoring System for Sleep Stages of Human Subjects. Washington DC: US Govt. Printing Office.

Reilly, T. and Walsh, T. J., 1981 “Physiological, psychological and performance measures during an endurance record for a 5-a-side soccer play". Brit.J.Spts Med. 15: 122-128.

Roberts, R., Gowda, K. S., Ludbrook, P. A. and Sobel, B. E., 1975 "Specificity of elevated serum MB creatine phosphokinase activity in the diagnosis of acute myocardial infarction". Amer.J.Cardiol. 36: 433-437.

Saltin, B. and Åstrand, P. O., 1967 “Maximal oxygen uptake in athletes”. J.Appl.Physiol. 23: 353.

Sanders, T. M. and Bloor, C. M., 1975 "Effects of repeated endurance exercise on serum enzyme activities in wellconditioned males". Med.Sci. in Spts. and Exer. 7: 44-47.

Seigel, A., Silverman, L., Evans, W. and Madar, D., 1982 "Elevated skeletal muscle creatine kinase MB isoenzyme levels in marathon runners. American College of Sports Medicine Annual Meeting". Med.Sci. in Spts. and Exer. $14: 171$.

Shapiro, C. M., 1981 "Sleep and the athlete". Brit.J.Spts. Med. 15: 51-55.

Shapiro, C. M., Bortz, R., Mitchell, D., Bartel, P. and Jooste, P., 1981 "Slow wave sleep and recovery period after exercise". Sci. 214: 1253-1254.

Shephard, R. J. and Sidney, K. H., 1975 "Effects of physical exercise on plasma growth hormone and cortisol levelsc in human subjects". In: J. H. Wilmore and J. F. Keogh (eds) Exercise and Sports Sciences Reviews Vol. 3. Academic Press, 1-30.

Superko, H. R., Catlin, M. J. and Smith, J. L., 1979 "Serum enzyme changes in prolonged endurance competition. American College of Sports Medicine Annual Meeting". Med.Sci. in Spts. and Exer. 11 (1): 82.

Thomas, V. and Reilly, T., 1975 "Circulatory, psychological and performance variables during 100 hours of paced continuous exercise under coriditions of controlled energy intake and work output". J.Hum.Mov.Stud. 1: 149-156.

Townshend, M. M. and Smith, A. J., 1972 "Factors influencing the urinary excretion of free catecholamines in man". Clin.Sci. 44: 253-265.

Von Euler, V. S., 1976 "Sympatho-adrenal activity in physical exercise". Med.Sci.Spts. 6: 165-173.

West, L. J., Janszen, H. H., Lester, B. K. and Cornelisoon, F. S., 1962 "The psychosis of sleep deprivation". 96: 66-70. 